\title{
Hakkâri ili baz metal yataklarının uzaktan algılama ile belirlenmesi
}

\author{
Determination of base metal deposits in Hakkâri province by remote sensing
}

\author{
Hacı Alim BARAN *1,a \\ ${ }^{1}$ Batman Üniversitesi, Mühendislik-Mimarlık Fakültesi, Jeoloji Mühendisliği Bölümü, 72100, Batman
}

• Geliş tarihi / Received: 21.11.2020 • • Düzeltilerek geliş tarihi / Received in revised form: 29.01.2021 • Kabul tarihi / Accepted: 03.02 .2021

\begin{abstract}
Öz
Eski çağlardan beri madencilik faaliyetlerine ev sahipliği yapan, 2010 yılından itibaren açılan maden ocakları ile tekrar ilgi odağı haline gelen Hakkâri, bölgede madencilik açısından incelenmesi önem arz eden illerden biridir. Bölgede gözlenen kayaçlar çoğunlukla karbonatlı kayaçlar olup, Paloezoyik (Permiyen)-Mesozoyik (Jura) yaş aralığına sahiptirler. Bu birimlerin üzerinde Kampaniyen - Alt Maastrihtiyen yaşlı Yüksekova melanjı, Paleosen ve Miyosen yaşlı sedimanlar uyumsuz olarak gözlenmektedir. Ülkemizin önemli metalojenik kuşaklarından birinde yer alan bölge baz metaller açısından potansiyeli yüksek alanlar arasında yer almaktadır. İnceleme alanı ve çevresinde hali hazırda keşfedilmiş ve/veya işletilen 20 adet maden yatağı mevcuttur. Bunlardan 5 tanesi endüstriyel hammadde ocağı (mermer), 15 tanesi $(10 \mathrm{~Pb}-\mathrm{Zn}, 2 \mathrm{Cu}, 3 \mathrm{Cr})$ ise metalik maden yataklarıdır. Uzaktan algılama ile maden aramada yaygın olarak kullanılan tekniklerden birisi de alterasyon tespitidir. Çalışma alanındaki madenler uzaktan algılama çalışmalarında yüksek başarı oranı ile tespit edilebilen demir veya demirli mineral içermektedir. Landsat 8 uydu görüntüsü üzerinde uzaktan algılama teknikleri (band oranlaması, kontrast germesi, renkli kompozit görüntü oluşturma) kullanılarak Hakkâri'de hali hazırda mevcut veya işletilen maden yataklarının konumları başarılı bir şekilde belirlenerek, 2 yeni potansiyel sahanın tespiti gerçekleştirilmiştir.
\end{abstract}

Anahtar kelimeler: Alterasyon, Hakkâri, Maden yatakları, Uzaktan algılama

\begin{abstract}
Hakkari, which has been hosting mining activities since ancient times and became the center of attention again with the mines opened since 2010, is one of the provinces in the region that is of importance in terms of mining. The rocks observed in the region are mostly carbonate rocks and they have the Paloezoic (Permian) - Mesozoic (Jurassic) age range. These units are unconformably overlain by Campanian - Lower Maastrichtian Yüksekova mélange, Paleocene and Miocene sediments. The region, which is located in one of the important metallogenic belts of our country, is among the areas with high potential in terms of base metals. There are 20 mineral deposits currently discovered and / or operated in the study area and its surroundings. 5 of them are industrial raw material quarries (marble), 15 of them (10 Pb- $\mathrm{Zn}, 2 \mathrm{Cu}, 3 \mathrm{Cr}$ ) are metallic mineral deposits. One of the techniques commonly used in mineral exploration with remote sensing is alteration detection. The mines in the study area contain iron or ferrous minerals that can be detected with a high success rate in remote sensing studies. By using remote sensing techniques (lithological mapping, band proportioning, contrast stretching, color composite image creation) on Landsat 8 satellite images, the locations of the existing or operated mineral deposits in Hakkâri have been successfully identified and 2 new potential sites have been determined.
\end{abstract}

Keywords: Alteration, Hakkâri, Ore deposits, Remote sensing

\footnotetext{
*a Hacı Alim BARAN; alimbaran@gmail.com, Tel: (0488) 217 41 14, orcid.org/ 0000-0003-4859-8446
} 


\section{Giriş}

İnsanoğlu eski çağlardan beri doğayı araştırmış, keşfetmek istemiş ve bu çabası sonucunda farklı açılardan doğadan faydalanmaya başlamıştır. Örneğin korunma ve avlanma ihtiyacı sonucunda kesici özelliğini keşfettiği obsidiyen gibi kayaç parçaları ile mızrak, balta, bıçak benzeri aletler yapmış, sertliği ve dayanıklılığ 1 sebebiyle bazalt, andezit gibi kayaçlardan sert cisimleri parçalama veya besinleri ögütmede faydalanmıştır. Paleolitik dönemdeki ilkel madencilik deneyimlerinden beri insanoğlu sürekli kendini geliştirmiştir. Madenler her dönemde farklı şekillerde insanların hayatında yer bulmuş, eski dönemlerde güç göstergesi olarak tanımlanırken günümüzde ise gelişmişlik ve kuvvetli ekonomi ile özdeşleştirilmektedir.

Madenler, üretimin temel girdisi olan hammadde ihtiyacını karşılaması sebebiyle kalkınma ve gelişimin ana lokomotiflerindendir. Üretim için gerekli teknolojiye sahip olmanın yanı sıra hammadde ihtiyacı özellikle stratejik öneme sahip madenler için çoğu zaman büyük sorunlara sebep olabilmektedir. Sanayileşme ve endüstriyel alanda gelişim hammaddeye ulaşım ile orantılı olarak gelişmekte, çoğu zaman savaş, ambargo, ekonomik yaptırım vb. siyasi sonuçları doğurmaktadır (Çiftçi vd., 2020). Bu nedenle özellikle gelişmekte olan ülkelerin dışa bağımlılığını azaltmak, üretim ve gelişmişliğini artırmak için gerekli hammadde ihtiyacının karşılanması stratejik öneme sahip bir hedefidir.

Ülkemizde de özellikle son on yılda madencilik alanında yaşanan olumlu gelişmeler ile yeraltı zenginliklerin keşfi ve işletilmeye başlanması ile hem üretim için ihtiyaç duyulan hammadde gereksiniminde dışa bağımlılığını azaltması hem de ekonomiye doğrudan katkısı ve istihdam olanakları nedeniyle giderek önem kazanmaktadır.

Ülkemiz 6 tektonik birlikten meydana geldiği için (Okay ve Tüysüz, 1999) hem tektonik olarak oldukça hareketlidir hem de farklı jeolojik ortamlar gözlenmesi nedeniyle jeolojik olarak oldukça zengin bir yapıya sahiptir. Bu nedenle Salda gölü, Pamukkale gibi görsel güzelliğe sahip jeolojik oluşumlar, Kapadokya, Kula, Nemrut krateri, Meke gölü gibi volkanizmaya bağlı gözlenen yapılar ile zengin ve çeşitli madenlerin oluşumlarını görmek mümkündür.

Madencilik insanların ihtiyaçlarına göre şekillenen ve gelişen bir alandır. Günümüzde artan endüstriyel üretim ve ihtiyaçları karşılamak için üretimin de aynı oranda artması kaçınılmazdır. $\mathrm{Bu}$ nedenle madenciliğin de gelişerek mevcut ihtiyaçları karşılayabilecek seviyelere ulaşması gerekmektedir. Dolayısıyla günümüzde eski proseslere oranla daha hizli, ekonomik ve minimum maliyet prensiplerine dayanan bir madencilik anlayışı gelişmiştir. Madenciliğin en problemli aşaması olan araştırma safhası diğer aşamalara oranla en çok zaman alan, maliyetli ve çoğu zaman düşük başarı oranına sahip bir aşama olduğundan günümüz teknolojilerinden yararlanılarak bu safhanın zaman, maliyet giderlerinin azaltılarak başarı oranının artırılması amaçlanmaktadır. Ülkemizde özellikle son 20 yılda maden aramada aktif olarak uydu görüntülerinin kullanılması ile madencilik sektöründe istenilen hedeflere daha düşük maliyetler ile ulaşması mümkün olmaya başlamış, bu konuda yapılan birçok bilimsel çalışma ile de konunun önemi vurgulanarak bilimsel literatüre olumlu katkılar sunulmuştur (Vural, 2006; Aydal, 2007; Karg1, 2007; Kavak, 2010; Özelkan vd., 2011; Vural vd., 2012; Kayadibi, 2015; Canbaz vd., 2017; Uysal vd., 2017; Başıbüyük ve Ekdur, 2018; Özgün ve San, 2018).

Bilindiği üzere madenlerin çoğu diğer jeolojik birimler veya yapıların aksine yeryüzünde gözlenmezler. Dolayısı ile bulunmaları hem masraflı hem de zor süreçler sonunda mümkün olabilmektedir. Bulunmass hedeflenen madenlerin özelliklerine bağlı amaca uygun olarak uydu görüntüleri kullanılması sonucunda detay inceleme yapilacak sahanın daraltılmas1 veya potansiyel sahaların direk tespiti ile arama safhasi optimum zaman -maliyet ve yüksek başarı oranı ile tamamlanabilir.

Uzaktan algılama ile maden aramada;

-Yüzeyde gözlenen madenlerin tespiti

-Madene eşlik eden alterasyon tiplerinin belirlenmesi

-Cevherleşmeye işaret eden bitkilerdeki anomalilerinin tespiti

-Yapısal unsurların tespiti

-Maden barındırabilecek litolojilerin belirlenmesi gibi yöntemler kullanılmaktadır. Aranan cevherleşmeye bağlı olarak bu yöntemlerin hepsi de kullanılabileceği gibi genellikle en s1k kullanılan yöntem alterasyonların tespitidir.

$\mathrm{Bu}$ çalışma kapsamında ülkemizin önemli maden alanlarından biri olan, Doğu Anadolu bölgesinin güney ucunda yer alan Hakkâri ili merkezi ve Çukurca ilçesi içerisinde gözlenen $\mathrm{Pb}-\mathrm{Zn}$ yatakları ele alınmıştır. İnceleme alanı, Hakkâri ilinin güney-güneybatısında olup, yaklaşı $1400 \mathrm{~km}^{2 ‘}$ lik bir alanı kapsamaktadır (Şekil 1). İnceleme alanı içerisinde Karakaya, Üzümlü, Meskantepe, 
Kurşuntepe, Armutlu, Oğul, Akkaya, Destan, Süvarihalil ve Haskel cevherleşmeleri yer almaktadır. Bölgede madencilik faaliyetleri 2004 yılında Üzümcü ve Meskantepe madenleri ile başlamış olup, 2007'de Kurşuntepe, 2009'da Karakaya, 2012'de Akkaya ve 2014'te Armutlu yataklarında devam etmektedir (Hanilçi vd., 2019). İnceleme alanı kapsayan uydu görüntülerinin değişik uzaktan algılama yöntemleri ile analizi ile mevcut maden sahalarının teyidi, olası potansiyel sahaların belirlenmesi amaçlanmıştır.

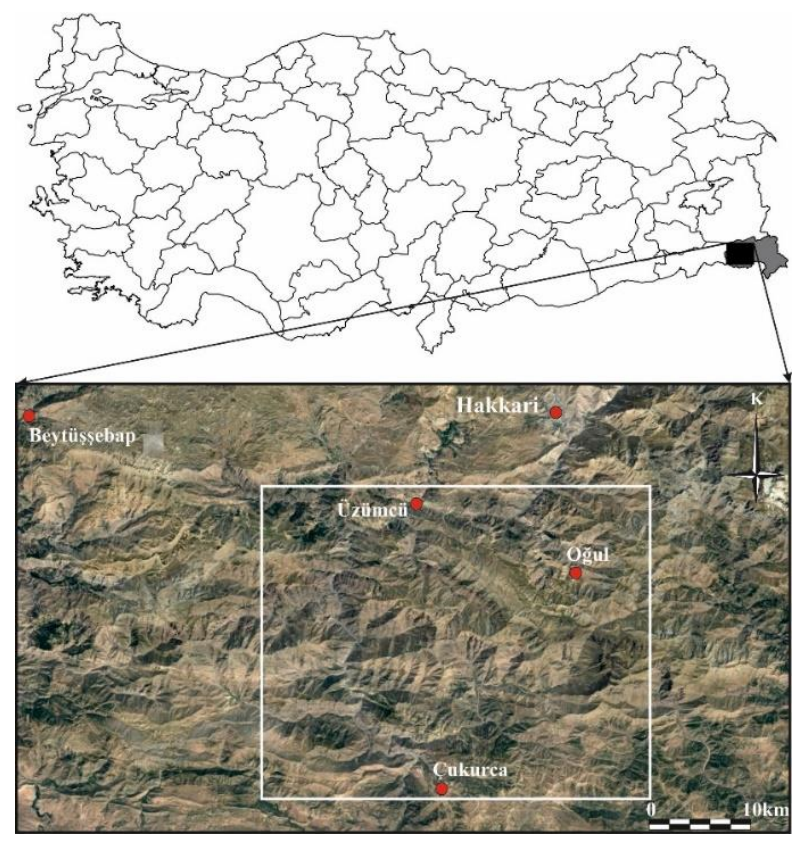

Şekil 1. İnceleme alanın yer bulduru haritası

\section{Materyal ve metot}

Çalışma alanında işletilmekte olan madenlerin konumları belirlenmiş, Hanilçi vd. 2019 tarafından hazırlanmış olan bölgenin jeoloji haritası sayısallaştırılarak sayısal yükseklik modeline giydirilmesi ile madenlerin jeoloji ve topoğrafya ile ilişkileri, stratigrafik seviyeleri gibi bilgiler elde edilmiştir. Uzaktan algılama çalışmalarında Envi, Mapinfo, Google Earth programları ile inceleme alanını kapsayan, Amerikan Jeolojik Araştırma Kurumu'ndan (USGS) alınan, 170-34 hat-sira numaral1, 07.08.2018 tarihli, UTM projeksiyonlu, WGS 84 datumlu Landsat-8 uydu görüntüsü kullanılmıştır. Uydu görüntüleri atmosferdeki şartlar, güneş ışınların geliş açısı ve verilerin kaydı aşamasında gözlenebilen sistematik hatalar nedeniyle sistematik olan veya olmayan bir takım hatalar içerir. Landsat 8 , görüntüler kaydedilirken geometrik ve radyometrik düzeltmeleri yapabilen teknik donanıma sahip bir uydudur. Uydu görüntülerinin kaydı esnasında sensörler araziden yayılan enerjiyi analog olarak algılar ve verilerin kaydı esnasında sahanın gerçek yansıma değerlerine göre bir takım sayısal değerlere dönüştürülerek kaydedilir. Bu nedenle çalışılacak sahadaki nesnelerin gerçek yansıma değerlerinin elde edilebilmesi amaciyla görüntü düzeltme (dönüştürme) işlemi gerçekleştirilir. Çalışma kapsamında Landsat 8 uydu görüntüsünün yansıma değerleri elde edildikten sonra band oranlama, band aritmetiği, renkli kompozit görüntülerin oluşturulması gibi uzaktan algılama teknikleri kullanılmıştır (Şekil 2).

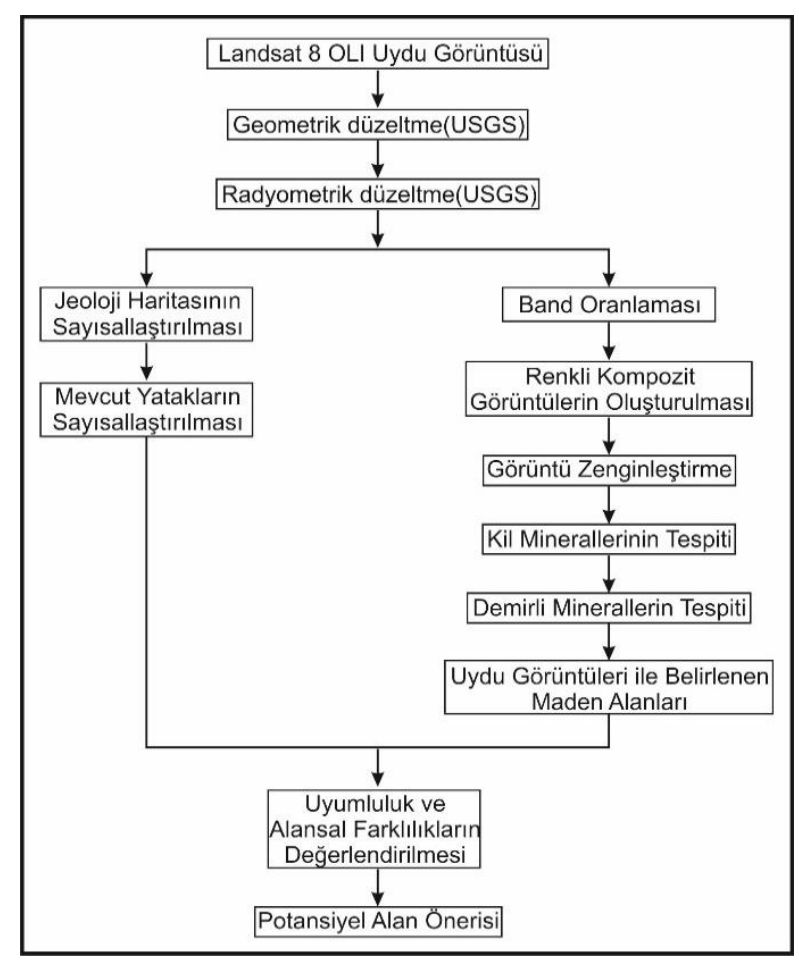

Şekil 2. İş akış şeması

\section{Bulgular}

Bilindiği üzere konumsal olarak birbirine yakın olan madenler kimi zaman belirli bir tabakaya bağlı olarak meydana gelirken kimi zaman benzer jeolojik ortamda oluşurlar. Her bilimsel çalışmada olduğu gibi maden arama, potansiyel alan tespiti çalışmalarında bölgenin jeolojik ve tektonik özelliklerinin belirlenmesi amaciyla literatür taraması ve mevcut cevherleşmeler hakkında bilgi edinilmesi çalışmanın sağlıklı bir şekilde yürütülmesi için önem arz etmektedir. $\mathrm{Bu}$ kapsamda Hanilçi vd. 2019 tarafından hazırlanmış olan bölgenin jeoloji haritası kullanılarak inceleme alanındaki işletilmekte olan cevherleşmelerin konumları belirlenmiştir. Madenlerin arazideki konumsal dağılımları, gözlendiği litolojilerin tespiti, tektonik yapılar ve topoğrafya ile ilişkilerini belirlemek ve potansiyel saha tespiti için ön inceleme amacıyla ilgili harita sayısallaştırılmış, sayısal yükseklik modeline giydirilmiştir. (Şekil 3). 


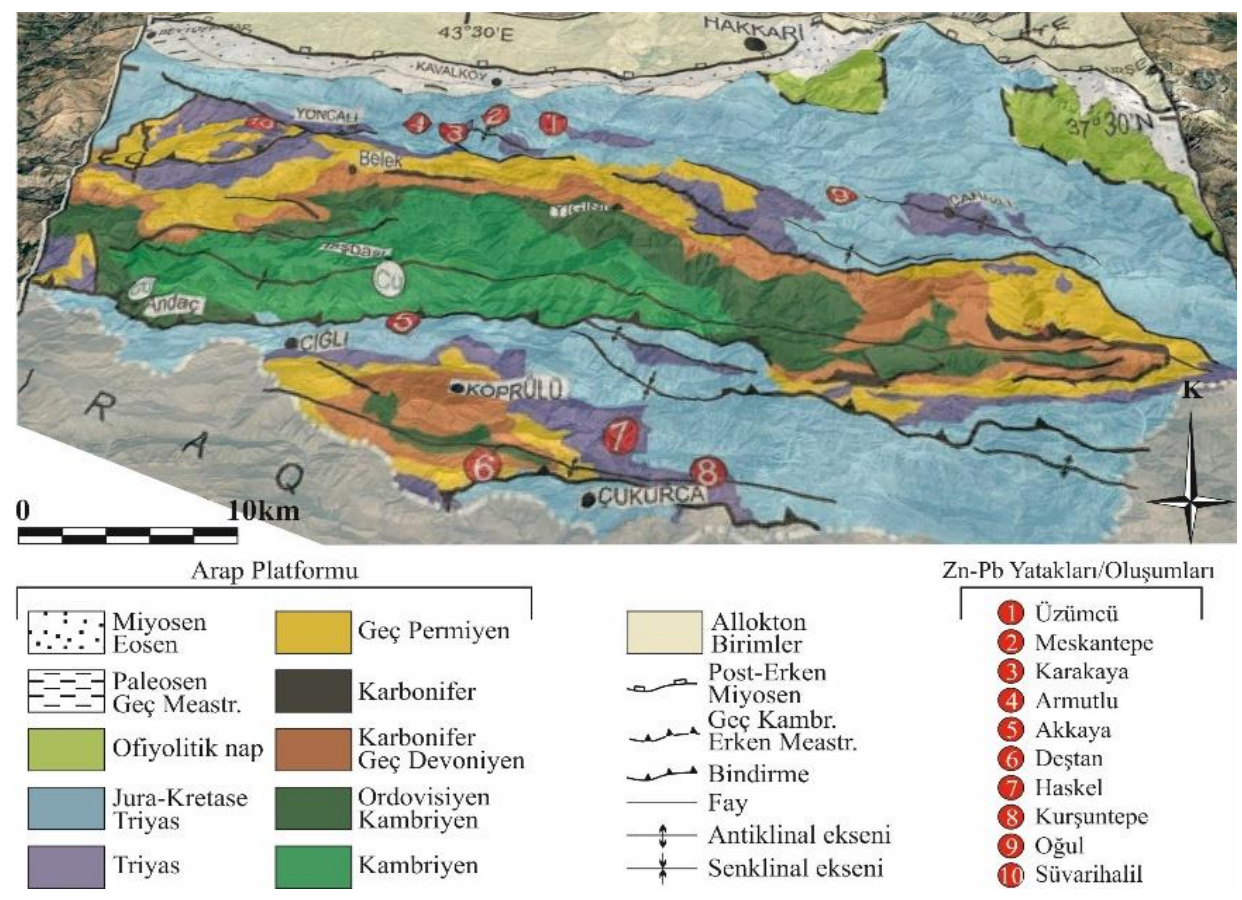

Şekil 3. İnceleme alanına ait jeoloji haritası (Hanilçi vd., 2019)

Uzaktan algılama çalışmaları kapsamında;

- Bölgenin jeolojisi ve mevcut yatakların jeolojik özelliklerinin belirlenmesi

- Tektonik yapılar ve madenler arasındaki ilişkilerin tespiti

- Uydu görüntüleri yardımıyla kil/hidroksil minerallerin tespiti

- Uydu görüntüleri kullanılarak bölgede yer alan demir/demirli minerallerin tayini

- Uzaktan algilama teknikleri kullanılarak maden sahalarının belirlenmesi (işletilen yatakların konumsal tespiti dâhil)

- Olasi potansiyel alan/alanların önerilmesi gerçekleştirilmiştir.
İnceleme alanında işletilmekte olan yatakların gözlendiği jeolojik birimler, cevherleşmelerin tektonik yapılarla ilişkilerinin incelenmesi sonucunda; inceleme alanının kuzeyinde yer alan cevherleşmelerin Jura-Kretase-Triyas yaşlı kireçtaşları içerisinde ve antiklinal ekseni ile yakından ilişkili olarak oluştuğu gözlenmiştir. Deştan cevherleşmesi hariç (Permiyen kireçtaşlarında gözlenmektedir) diğer cevherleşmelerin Triyas yaşlı kireçtaşları içerisinde ve yine antiklinal eksenine yakın olarak oluştukları belirlenmiştir. Cevherleşmelerin mineral parajenezleri incelenerek (Tablo 1) buna bağlı olarak uzaktan algılamada kullanılacak teknikler belirlenmiştir.

Tablo 1. İnceleme alanındaki mevcut yatakların mineral birliktelikleri

\begin{tabular}{l|l}
\hline Cevherleşme Sahası & Mineral parajenezi \\
\hline Üzümlü & $\begin{array}{l}\text { Simitsonit, hidrozinkit, zinkit, hemimorfit, serüzit, anglezit, sfalerit, galen, pirit, } \\
\text { barit, kalsit, dolomit (Hanilçi ve Öztürk 2008, Santoro vd., 2013, Karakaya } \\
\text { Şirketi, 2015) }\end{array}$ \\
\hline Meskantepe & $\begin{array}{l}\text { Simitsonit, hidrozinkit, zinkit, serüzit, anglezit, hemimorfit, götit, sfalerit, galen, } \\
\text { pirit, barit, kalsit, dolomit, siderit, kuvars (Hanilçi vd., 2019) }\end{array}$ \\
\hline Karakaya & $\begin{array}{l}\text { Simitsonit, hemimorfit, hidrozinkit, zinkit, serüzit, anglezit, götit, siderit, kalsit, } \\
\text { dolomit, barit, galen, sfalerit, pirit (Hanilçi ve Öztürk 2008, Santoro vd., 2013, } \\
\text { Karakaya Şirketi, 2015) }\end{array}$ \\
\hline Armutlu & $\begin{array}{l}\text { Simitsonit, hemimorfit, hidrozinkit, zinkit, serüzit, anglezit, götit, siderit, kalsit, } \\
\text { dolomit, barit, galen, sfalerit, pirit (Hanilçi vd., 2019) }\end{array}$ \\
\hline Akkaya & Simitsonit, serüzit, götit, limonit, galen, barit (Hanilçi vd., 2019) \\
\hline Deştan & Simitsonit, serüzit, galen (Hanilçi vd., 2019) \\
\hline Kurşuntepe & Sfalerit, galen, pirit, barit, dolomit, kalsit, kuvars (Hanilçi vd., 2019) \\
\hline Oğul & $\begin{array}{l}\text { Galen, sfalerit, pirit, simitsonit, serüzit, anglezit, limonit, götit, barit (Hanilçi vd., } \\
\text { 2019) }\end{array}$ \\
\hline
\end{tabular}


Çalışma alanındaki cevherleşmelerin mineral birlikteliklerinin incelenmesi sonucunda hepsinin demirli mineraller (pirit, götit, hemimorfit, limonit) içermesi ve hepsinde hidrotermal alterasyonun gözlenmesi sebebiyle literatürde alterasyon ve demirli minerallerin tespitinde yaygin olarak kullanilan;

- Kil mineralleri ve demir içeren minerallerin tespiti için 6/7 band oranı (Şekil 4a, Sabin, 1999)

- Hidroksil minerallerin belirlenmesi için oluşturulan $(6 / 5) *(4 / 5)$ görüntüsü (Şekil $4 b$, Sultan vd. 1986)

- Demirli minerallerin tespitine olanak taniyan yöntemler

- $4 / 5$ band oranı (Şekil 4c, Bersi, 2016)

- 5/4 band oran1 (Şekil 4d, Bersi, 2016)

- Demir indeksi hesabı (Şekil 4e, Bersi,

2016)

- $\mathrm{R}(4 / 2) \mathrm{G}(5 / 4) \mathrm{B}(5 / 7)$ renkli kompozit görüntü (Şekil 5a, Salem ve Gammal, 2015)

- $\mathrm{R}(4 / 2) \mathrm{G}(5 / 7) \mathrm{B}(4 / 5)$ renkli kompozit görüntü (Şekil 5b, Salem ve Gammal, 2015)

- $\mathrm{R}(4 / 2) \mathrm{G}(5 / 7)$ B (5/4) renkli kompozit görüntü (Şekil 5c, Salem ve Gammal, 2015)

- $\mathrm{R}(4 / 5) \mathrm{G}(5 / 6)$ B (6/7) renkli kompozit görüntü (Şekil 5d, Bersi, 2016)

- $\mathrm{R}(5 / 7) \mathrm{G}(4 / 5) \mathrm{B}(4 / 2)$ renkli kompozit görüntü (Şekil 5e, Salem ve Gammal, 2015)

- $\mathrm{R}(5 / 7) \mathrm{G}(5 / 4) \mathrm{B}(4 / 2)$ renkli kompozit görüntü (Şekil 5f, Salem ve Gammal, 2015) uzaktan algılama teknikleri kullanılmıştır.

Uzaktan algılamada kullanılan band oranları iki farklı enerji aralığı kaydını içeren bandın matematiksel olarak oranlaması olduğundan elde edilen görüntü siyah-beyaz renklidir. Oranlanan bantların enerjileri ve belirlenmek istenilen mineralin bu enerjilere tepkisine bağlı olarak elde edilen görüntülerde sonuç kimi zaman açık kimi zaman koyu renklerle ifade edilir. 6/7 band oran kil mineralleri ve demir oksitlerin tespiti için kullanılır ve koyu alanlar kil minerallerini işaret etmektedir (Şekil 4a). 6/5*4/5 band oranı hidroksil mineraller ve $\mathrm{Fe}-\mathrm{Al}$ silikatların tespitinde kullanılır (Şekil 4b). $4 / 5$ ve $5 / 4$ band oranları demir tespiti için kullanılan bir oran olup, elde edilen görüntülerde 4/5' deki beyaz (Şekil 4c), 5/4'deki siyah (Şekil 4d) renkler demirli alanları işaret etmektedir (Bersi, 2016). Bersi (2016) tarafindan önerilen bir diğer demir tespit metodu ise demir cevheri indeksi hesaplamasıdır. $\mathrm{Bu}$ yöntemde demiri cevher indeksi aşağıda verilen 1 numaralı denklem ile hesaplanmakta ve beyaz alanlar demirli alanları işaret etmektedir (Şekil 4e). Bu yöntem uygulanırken denklem 1 de belirtilen bant aritmetiğinin yanı sıra elde edilen görüntüde demir cevheri için spesifik radyometrik aralığı olan 0,88 2,77 absorbsiyon için kontrast germesi uygulanmalıdır.

$$
\begin{aligned}
& \text { Demir Cevheri İndeksi }= \\
& \qquad\left(2 * \frac{B 6}{B 5}\right)-\left(3 * \frac{B 5}{B 7}\right)
\end{aligned}
$$

Bilindiği üzere beyaz ışık üç ana renkten meydana gelir ve uydu görüntülerinde kırmızı (R), yeşil (G) ve mavi (B) olmak üzere bu üç ana renk bandına kendi enerjileri yüklenirse ilgili arazinin doğal veya gerçek renk görüntüsü elde edilmiş olur. Bunun dışındaki enerjiler kullanılarak oluşturulan bütün görüntüler sahte renkli (false colour) görüntülerdir ve incelenen arazi çoğu zaman aykırı renklerde görülür. Oluşturulan renkli kompozit görüntülerden elde edilen sonucun ayırt edilebilme yeteneğinin artırılması ve görsel açıdan anlaşılırlığını artırmak amacıyla görüntünün yansıma değerlerine göre en iyi sonuç veren kontrast germe yöntemi uygulanır. İnceleme alanında elde edilen görüntülerin histogram değerleri normal dağılım sergilediğinden Gaussian kontrast germe tekniği uygulanmıştır.

Demirli mineraller ile kil minerallerinin tespiti amaciyla gerçekleştirilen sorgularda cevher ve/veya alterasyon minerallerini işaret eden alanların değerlendirilmesi sonucunda tespit edilen alanların bir kısmının hali hazırda işletilmekte olan maden ocaklarını işaret ettiği belirlenmiş, dolayısıyla mevcut yatakların konumlan başarılı bir şekilde belirlenerek teyidi gerçekleştirilmiştir. İnceleme alanındaki cevherleşmeler tabaka bağımlı SEDEX tip cevherleşmeler olduğundan (Santoro vd., 2013; Hanilçi vd., 2019) benzer litoloji, stratigrafik seviye ve tektonik ortamda gözlenmeleri olağandır. Ayrıca tespit edilecek yeni sahalarında mevcut yataklar ile benzer özelliklere sahip olmaları, ayn1 litoloji, tektonik ortamda gözlenmeleri beklenen bir sonuçtur. Bu kapsamda cevher ve/veya alterasyon mineralleri için olumlu sorgulama sonuçları alınan mevcut maden yatakları ile aynı kayaçlar içerisinde ve benzer tektonik ortamda gözlenen 2 adet lokasyon, inceleme alanında maden oluşumuna sebep olan sistemin bir parçası oldukları şeklinde yorumlanarak potansiyel cevherleşme alanı olarak önerilmiştir. İlgili lokasyonlar Şekil 4 ve Şekil 5 'teki uydu görüntülerinde 1 ve 2 numaralı alan olarak gösterilmiştir. 


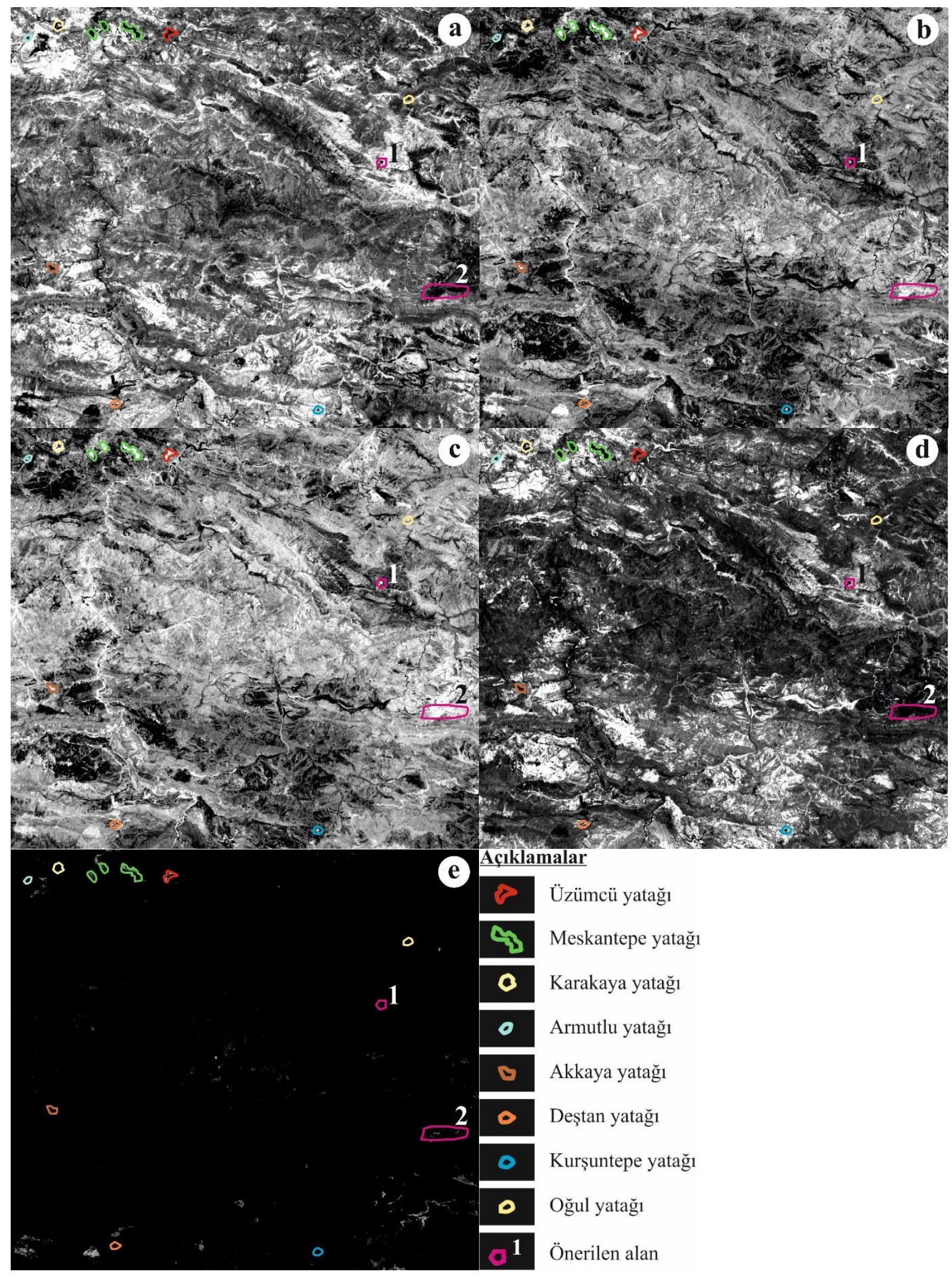

Şekil 4. İnceleme alanına ait band aritmetiği ile oluşturulan uydu görüntüleri (a: 6/7, b: (6/5)*(4/5), c:4/5, d: $5 / 4$, e: demir indeksi) 


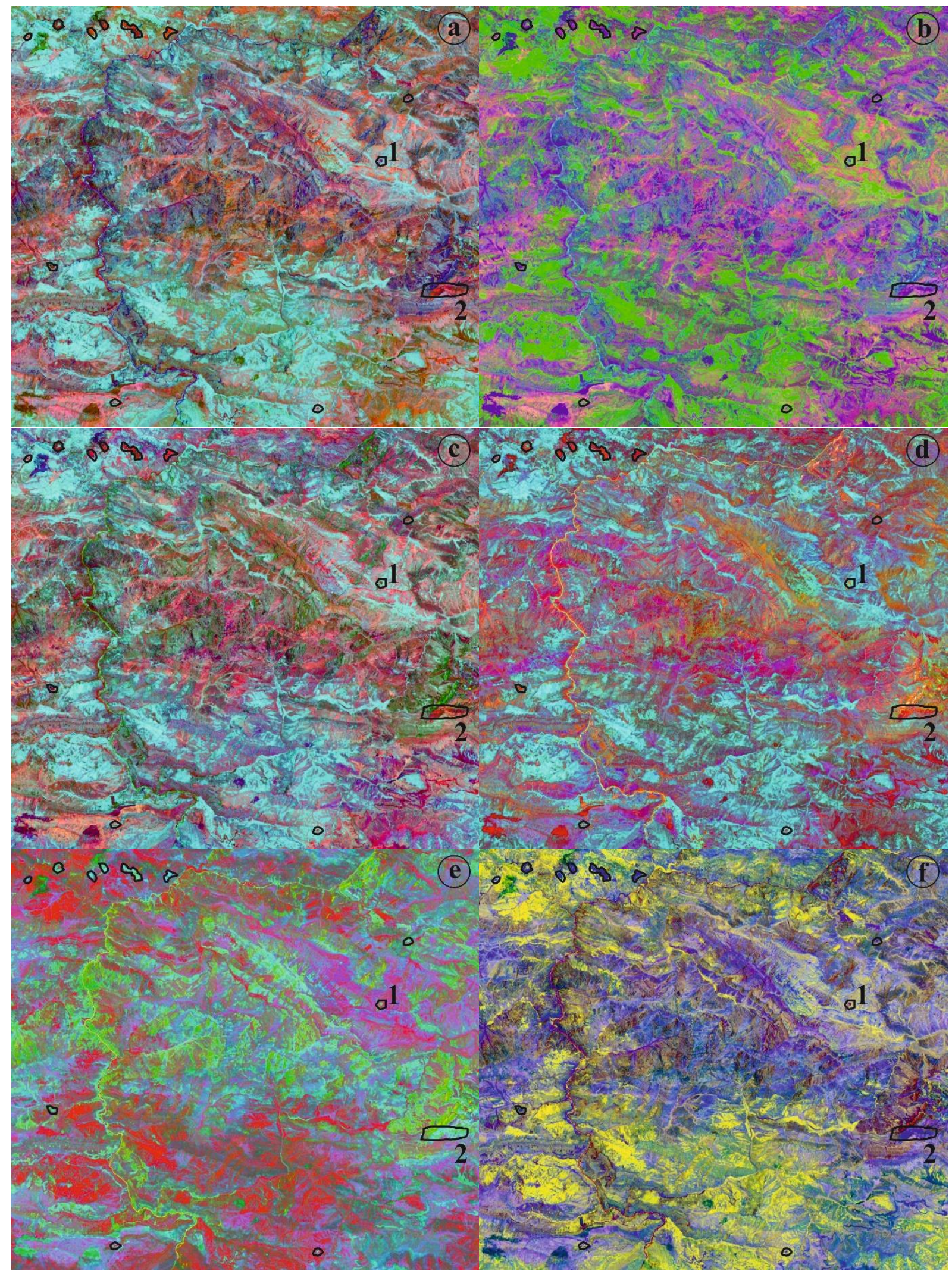

Şekil 5. İnceleme alanına ait renkli kompozit uydu görüntüleri (a: R(4/2) G (5/4) B (5/7), b: R(4/2) G (5/7) B (4/5), c: R(4/2) G (5/7) B (5/4), d: R(4/5) G (5/6) B (6/7), e: R(5/7) G (4/5), B(4/2), f: R(5/7) G (5/4) B (4/2))

\section{Tartışma ve sonuçlar}

İnceleme alanının jeolojik ortamı, metalojenik zon bilgileri, gözlenen litolojik birimler ve önceki çalışmalardan derlenen bilgilerin yorumlanması sonucunda bölgenin maden açısından yüksek potansiyele sahip olduğunu söylemek mümkündür. Halı hazırda 6 madenin aktif bir șekilde işletilmesi ve bölgede arama faaliyetlerinin artarak devam 
etmesi bölgenin potansiyelinin bir diğer göstergesidir.

Cevher ve/veya alterasyon oluşumunu işaret eden demirli mineraller ile kil minerallerinin tespiti amaciyla band oranlar1 $(6 / 7,4 / 5,5 / 4),(6 / 5) *(4 / 5)$ ve demir indeksi hesab1 ile renkli kompozit görüntüler (4/2 5/4 5/7; 4/2 5/7 4/5; 4/2 5/7 5/4; 4/5 $5 / 6$ 6/7;5/7 4/5 4/2;5/7 5/4 4/2) oluşturulmuştur. Uygulanan uzaktan algilama teknikleri ile elde edilen spektra değerlerinin yorumlanması sonucunda mevcut yatakların konumları başarılı bir şekilde belirlenmiştir. Mevcut cevherleşmeler ile benzer yansıma değerlerine sahip, yan kayaç litolojisi ve tektonik ortam bakımından benzer özellikler sunan 2 alan, potansiyel cevherleşme alanı olarak önerilmiştir.

$\mathrm{Bu}$ çalışma, arazi çalışmaları ve jeolojik gözlemler açısından Hakkâri gibi zorlu coğrafik koşullara sahip sahalarda uzaktan algılama yöntemlerinin kullanılarak maden sahalarının ve/veya potansiyel alanların belirlenmesi ile sonraki çalışmaların bu sonuçlara göre planlanması sonucunda hem zaman hem ekonomik kazanç sağlanması açısından önemli olduğunu göstermiştir. Ayrıca bu teknikler güvenlik açısından hassas olan sahalarda da rahatlikla uygulanarak sadece belirlenen alanlarda arazi çalışması planlanması ile güvenlik zafiyeti minimuma indirilmesi mümkündür.

$\mathrm{Bu}$ tarz çalışmalar özellikle Hakkâri gibi iş olanakları ve istihdam sahaları az olan illerde hem sayı hem içerik yönünden artırılarak yapılmasıyla, yeni istihdam alanlarının oluşturulması ve il ekonomisine olumlu katkılar sağlaması açısından stratejik önem arz etmektedir.

\section{Kaynaklar}

Aydal, D. ve Vural, A. (2007). Alakeçı-Kısacık (Bayramiç-Balıkesir) cevherleşme bölgesinin Landsat 7 ETM+ kullanılarak Crosta tekniği ile incelenmesi. Selçuk Üniversitesi MühendislikMimarlık Fakültesi Dergisi, 23(3), 29-40.

Başıbüyük, Z. and Ekdur, E. (2018). Determination of iron minerals with landsat ETM+, Kırşehir, Turkey. Mineral Resources Management, 34(3), 23-36. https://doi.org/10.24425/122579

Bersi, M. Saibi, H. and Chabou, M. C. (2016). Aerogravity and remote sensing observations of an iron deposit in Gara Djebilet, southwestern Algeria. Journal of African Earth Sciences, 116, 134-150.

http://dx.doi.org/10.1016/j.jafrearsci.2016.01.00 4
Canbaz, O. Gürsoy, Ö. ve Gökçe, A. (2017). Aster uydu görüntüleri ile hidrotermal alterasyon alanlarının belirlenmesi: Ağmaşat Yaylası-Zara (Sivas) / Türkiye örneği. Cumhuriyet Sci. J., 38(3), 419426. http://dx.doi.org/10.17776/csj.340473

Çiftçi, A. Ural, M. N. ve Vural, A. (2020). Baz metallerin dünya siyasi tarihindeki önemli olaylarla bağlantısının retrospektif literatür taraması yöntemi ile araştırılması. International Social Sciences Studies Journal, 6(60), 14531451. http://dx.doi.org/10.26449/sssj.2240

Gibson, P. J. and Power, C. (2000). Introductory remote sensing: digital image processing and applications, London: Routledge. https://doi.org/10.1017/S0016756801244951

Hanilçi, N. and Öztürk, H. (2008). Hakkâri region Zn$\mathrm{Pb}$ deposits: preliminary evidence for their geological features and formation. Proceedings symposium on geology and mining of $\mathrm{Pb}-\mathrm{Zn}$ deposits of Turkey (pp244-264). Istanbul.

Hanilçi, N. Öztürk, H. and Kasapçi, C. (2019). Carbonate-hosted $\mathrm{Pb}-\mathrm{Zn}$ deposits of Turkey, F. Pirajno, T. Ünlü, C. Dönmez, M.B. Şahin (Ed.) in: Mineral Resources of Turkey (pp.497-534). Switzerland: Springer-Verlag. https://doi.org/10.1007/978-3-030-02950-0

Karakaya İşletmesi. (2015). The ore zones of Karakaya $\mathrm{Pb}$-Zn deposits and Ore Potential. p25.

Karg1, H. (2007). Principal components analysis for borate mapping. International Journal of Remote Sensing, 28(8), 1805-1817. https://doi.org/10.1080/01431160600905003

Kavak, K. S. (2010). Recognition of gypsum geohorizons in the Sivas Basin (Turkey) using ASTER and Landsat ETM+ images. International Journal of Remote Sensing, 20(20), 4583-4596.

https://doi.org/10.1080/01431160500185607

Kayadibi, Ö. (2015). Landsat 7 ETM+ ve ASTER görüntüleri ile Yusufeli-Tekkale (Artvin-KD Türkiye) çevresindeki hidrotermal alterasyonların incelenmesi. Türkiye Jeoloji Bülteni, $\quad 58(2), \quad 29-54$. https://doi.org/10.25288/tjb.298558

Okay, A. I. and Tüysüz, O. (1999). Tethyan sutures of northern Turkey. Durant, B., Jolivet, F., Horvath, F., Seranne, M. (Ed.). The Mediterranean basin: Tertiary extension within the Alpine orogen (pp475-515). London: Geological Society, Special Publication. http://dx.doi.org/10.1144/GSL.SP.1999.156.01. 22

Özgün, M. E. and San B. T. (2018). Mapping evaporite minerals using Aster TIR image in Beypazari, 
Ankara (Turkey). 9th International Symposium on Eastern Mediterranean Geology (pp 241242), Antalya.

Özelkan, E. Karaman, M. ve Uça Avcı, Z. D. (2011). Madencilik faaliyetlerinin izlenmesinde uydu görüntülerinin kullanılabilirliği. Kazdağları örneği. International Symposium on Kaz Mountains (Mount Ida) and Edremit (Global Change in the Mediterranean Region) (pp. 227233). Balıkesir.

Sabins, F. F. (1999). Remote sensing for mineral exploration. Ore Geology Reviews, 14, 157-183. https://doi.org/10.1016/S0169-1368(99)00007-4

Salem, S. M. and El Gammal, E. A. (2015). Iron ore prospection East Aswan, Egypt, using remote sensing techniques. Ore Geology Reviews, 18, 195-206.

https://doi.org/10.1016/j.ejrs.2015.04.003

Santoro, L. Boni, M. Herrington, R. and Cleeg, A. (2013). The Hakkari nonsulide $\mathrm{Zn}-\mathrm{Pb}$ deposit in the context of other nonsulide $\mathrm{Zn}-\mathrm{Pb}$ deposits in the Tethyan Metallogenic Belt of Turkey. Ore
Geology Reviews, 53, 244-260. https://doi.org/10.1016/j.oregeorev.2013.01.011

Sultan, M. Arvidson, R. E. and Sturchio, N. C. (1986). Mapping of serpentinites in the Desert of Egypt using Landsat Thematic Mapper data. Geology, 14, 995-999. https://doi.org/10.1130/00917613(1986)14\%3C995:MOSITE\%3E2.0.CO;2

Uysal, M. Turgut, B. Polat, N. Dereli, M. A. ve Yalçın, M. 2017. Uzaktan algılama teknikleri ile açık maden ocaklarında bor minerallerinin tespiti. Afyon Kocatepe Üniversitesi Fen ve Mühendislik Bilimleri Dergisi, 17 (Özel Sayı), 270-276.

Vural, A. (2007). Bayramiç ve çevresindeki altın zenginleşmelerinin araştırılması. Doktora Tezi, Ankara Üniversitesi Fen Bilimleri Enstitüsü, Ankara.

Vural, A. Çorumluoğlu, Ö. ve Asri, İ. (2012). Eski Gümüşhane (Süleymaniye) ve yakın çevresindeki alterasyon alanlarının Landsat uydu görüntüsü kullanılarak Crosta tekniği ile araştırılması. Gümüşhane Üniversitesi Fen Bilimleri Enstitüsü Dergisi, 2(1), 36-48. 